\title{
Liver Transplantation in the Elderly: An Evidence Based Review on Patient Outcome, Selection and Management Strategies
}

\author{
Lei Yu, Robert Carithers \\ Division of Gastroenterology and Hepatology, University of Washington, Seattle, Washington, USA \\ Email: LeiY@medicine.washington.edu
}

Received 3 May 2014; revised 18 June 2014; accepted 30 June 2014

Copyright (C) 2014 by authors and Scientific Research Publishing Inc.

This work is licensed under the Creative Commons Attribution International License (CC BY).

http://creativecommons.org/licenses/by/4.0/

(c) (i)

\begin{abstract}
There has been a steady increase in the age of potential recipients for liver transplantation over the past two decades. While patients older than age 60 , on average, did not do as well as younger patients after transplantation, optimizing patient selection could minimize this discrepancy. It is appropriate to evaluate functional elderly patients without significant medical co-morbidities for liver transplantation for the same indications as younger patients. For elderly patients with hepatocellular carcinoma and otherwise compensated liver disease, however, it is important to consider alternative treatment modalities that could provide similar survival. Elderly candidates who became too ill should be compassionately counseled away from transplantation based on existing prognostic models that can accurately predict post-transplant mortality. Finally, elderly transplant candidates and recipients may benefit from a more tailored management strategy in terms of donor risk matching and less immunosuppression.
\end{abstract}

\section{Keywords}

Liver Transplantation, Review, Management Strategies

\section{Introduction}

Liver transplantation is the only curative treatment for decompensated cirrhosis, hepatic malignancies and fulminant hepatic failure [1]. Over the past two decades there has been a steady increase in the age of potential recipients for transplantation. At present, $75 \%$ of patients on the waiting list for liver transplantation in the United States are older than 50 years of age (Figure 1) [2]. Furthermore, the proportions of liver transplant recipients who were 60 years of age or older rose from 15\% in 1990-1995, to 23.4\% in 2006-2010. Mirroring this trend, 


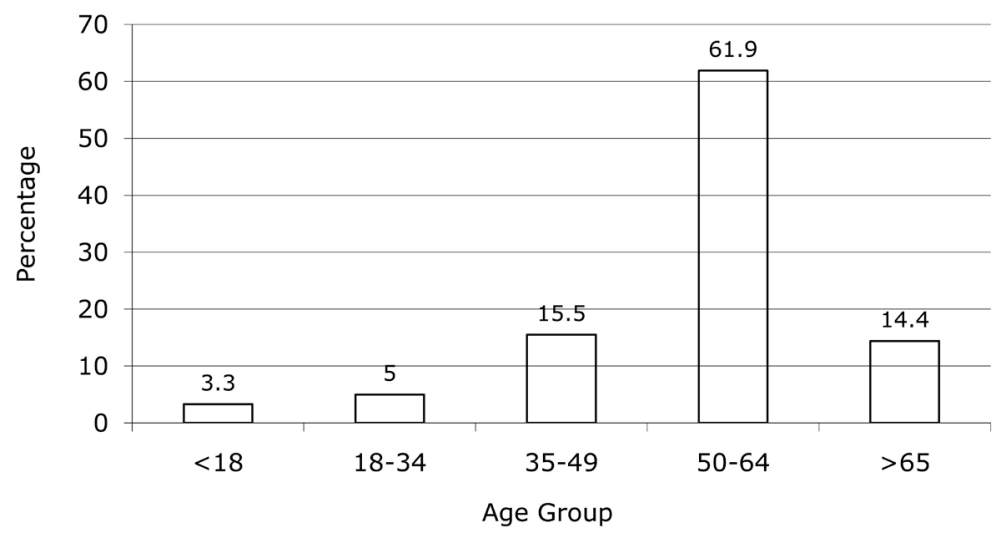

Figure 1. Percentage of patients on the liver transplantation waitlist in each age group in 2010 .

the proportion of liver donors who were 60 years of age or older increased even more sharply, from $5.7 \%$ to 13.6\% (Figure 2) [2]. Consideration of elderly individuals, both as recipients and donors, is now a daily occurrence at liver transplant centers throughout the world. Given the controversy associated with allocating scarce donor organs to older recipients [3] [4], a discussion of liver transplantation in the elderly is timely. The current review addresses three questions pertaining to liver transplantation of the elderly:

1) Is liver transplantation in the elderly feasible?

2) How to select elderly patients who have a realistic chance of long-term survival and high quality of life after transplantation?

3) How to improve medical management of elderly patients who have undergone liver transplantation?

\section{Is Liver Transplantation in the Elderly Feasible?}

Refinement in medical, surgical and peri-operative care of liver transplant patients over the past two decades allow transplant programs now to consider elderly patients who would have been unacceptable candidates in the past. Gradual accumulation of experiences may have contributed to the increase in age of recipients who are considered elderly, from those older than 50, to those older than 60 and now even to those older than 70 years of age [5]-[9]. A large number of reports on the outcome of elderly liver transplant recipients have been published [5][22]. Keswani et al. has provided an excellent review on the majority of these studies [23]. Most of the authors used age 60 or 65 as the cutoff to compare older vs. younger patients, three used 70 [6]-[9]. All but one study reported experience with deceased donor transplantation [22]. We will highlight salient features of these reports in order to answer our proposed question.

Zetterman et al. published the only report that provided data on the proportion of patients who ultimately underwent transplantation among those being evaluated for the procedure, $54.2 \%$ for age 60 or older, $54.8 \%$ for age less than 60 [21]. This suggests a lack of bias towards older patients. The authors found a significantly lower 1-year survival in the older age group, $81 \%$ vs. 90\%, where the majority of deaths occurred within the first 6 months of transplantation. Patients in the two age groups who survived 1 year after transplantation had a similar degree of improvement in their quality of life indices.

While 1-year survival rates for elderly recipients were fairly consistent among studies, ranging between $75 \%$ $85 \%$, long-term survival rates tend to vary more significantly across studies. From England, Cross et al. showed excellent outcomes for recipients who were older than 65 years of age compared to recipients who were 60 - 64 and 18 - 59 years of age [14]. The 5-year survival rates in the 3 groups were $73 \%, 77 \%$ and $73 \%$ respectively. The Mayo Clinic reported a similar experience from 1998-2004, showing virtually identical 5-year survival rates among 42 recipients age 70 or older (73\%) and a carefully matched control group who were younger than 60 years of age (76\%) [6]. In sharp contrast to these reports, two other studies reported a more dismal outcome. Using single center data from1984 to 1997, Collins et al. compared survival between 91 recipients age 60 and older with 387 younger adults. The 5 and 10 -year patient survival was $52 \%$ and $35 \%$ in the older group, compared to $75 \%$ and $60 \%$ in the younger group. A recent analysis using data from the United Network of Organ Sharing (UNOS) database between 2003-2008 also showed a disappointing, 55\%, 5-year survival for recipients 


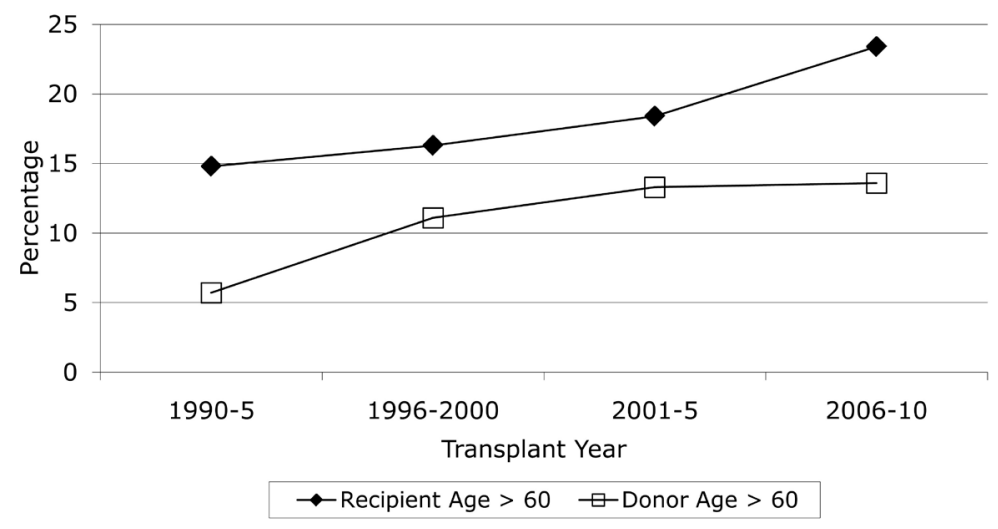

Figure 2. Rising proportion of liver transplant recipients and donors who are older an 60 years of age from 1990-2010.

age 70 and older [8]. Recipients age 70 or greater was associated with a $60 \%$ increase in mortality compared to those younger than 70 after accounting for other predictors of post-transplant survival (hazard ratio 1.626, $\mathrm{p}>$ 0.0001). These varied experiences suggest practice patterns of individual centers may affect post-transplant survival. But on a national level, at least in the United States, when the effect of individual transplant centers is being "averaged", elderly recipients do not do as well as younger patients in the long-term.

There are 2 important analytical considerations when evaluating the independent effect of age on survival post-transplantation. First, because age is a continuum, dividing a cohort at an arbitrary point, i.e. 60, may not fully capture the effect of aging. Second, because there are other factors affecting post-transplant survival, such as liver disease severity and donor quality, it is important to account for such factors during analyses. Three reports made serious attempts at addressing these 2 issues [17] [18] [21]. Age 60 was shown to be a very "good" cut-off point: the 1-year post-transplantation mortality was nearly the same among recipients whose age was between 30 and 60 [21], it became accelerated after this age [17] [21]. It also became clear that age greater than 65 [18] or 66 [17] was associated with even worse survival. After accounting for other factors affecting post-transplant survival, Zetterman (hazard ratio 1.96, 95\% CI 1.17 - 3.30) and Levy (hazard ratio 2.3, 95\% CI 1.6 - 3.5) both reported recipient age 60 or older to be an independent risk factor for mortality at 1-year post-transplantation.

Taken together, liver transplant recipients age 60 and older do not do as well as younger patients, especially after accounting for other predictors of post-transplant survival. Even though the majority of elderly recipients tolerated the surgery, the lower survival was clinically apparent in the short-term, and became more pronounced in the long-term. Other notable, but subtle differences, between older and younger recipients may explain this discrepancy in survival, assuming older recipients passed the rigorous medical examination before being considered eligible for transplantation. Zetterman et al. found older recipients were more likely to have poor nutritional status and muscle wasting, and slightly, though statistically significant, worse renal function (serum creatinine 1.4 vs. $1.2 \mathrm{mg} / \mathrm{dL}$ ) [21]. These factors are known to be independent predictors of worse post-transplant survival [24] [25]. Elderly patients who were more ill, for example, having Child's C cirrhosis rather than Child's A or B, or were hospitalized in the ICU, did especially poorly: fewer than $40 \%$ of patients age 65 or older who underwent transplant from the ICU survived at 1 year [18]. It is worth noting that elderly recipients who achieved excellent survival in the two aforementioned studies were less ill physiologically than their younger counterparts based on the reported Child's class, serum bilirubin and albumin levels [6] [14]. Avoiding these patients may partly explain why some centers are able to achieve excellent long-term outcome among elderly candidates. The answer to our proposed question is "yes", but patient selection is crucial, which we will discuss in detail in the next section.

\section{How to Select Elderly Patients Who Have a Realistic Chance of Long-Term Survival and High Quality of Life Following Liver Transplantation?}

By combining a thorough medical evaluation focusing on known characteristics of the elderly population and new prognostic models on the risk of liver transplantation, it is possible to identify older candidates who will have a reasonable long-term post-transplant survival. This process is critical to ensure proper utilization of scarce donor 
organs because elderly patients in general, as we have discussed, do not do as well as their younger counterparts. We will also discuss the special case of elderly patients with hepatocellular carcinoma but otherwise well compensated cirrhosis, a scenario in which treatment other than transplantation may be similarly efficacious.

\subsection{Pre-Liver Transplant Medical Evaluation of the Elderly}

In the general population, the elderly are more likely to have coronary artery disease [26], decreased renal function [27], osteoporosis [28] and malignancies [29] than younger people. The life-time risk of fatal coronary artery disease or nonfatal myocardial infarction among individuals with no risk factors is more than four-fold higher for those at age 65 (9.6 \% until age 90) compared to those at age 45 (1.7\% until age 80) [30]. Renal function also declines steadily during aging [31]. There is a progressive fall in glomerular filtration rate (GFR) after age 40 [32], a decrease in renal "reserve" and impaired sodium and water handling [33]. Almost half of elderly individuals was estimated to have chronic kidney disease [34]. Osteoporosis with or without decreasing functional status is another common complication leading to increased morbidity and mortality, both in the elderly and in patients with cirrhosis [35] [36]. Finally, the risk of most cancers increases with age [29], which is reflected by the fact that the median age at diagnosis for most cancers is in the mid sixties.

The medical co-morbidities seen in older patients with liver disease likely mirror that of the general population. Hoshida et al. reported a 90\% prevalence of medical co-morbidities in an elderly cohort of 135 Japanese patients with chronic liver disease [37]. Thirty-one percent of these patients had cardiovascular disease and $21 \%$ had extra-hepatic cancer. In addition, of the 45 deaths that occurred during follow-up, only $40 \%$ were from liver related causes. This study would suggest that liver transplantation is unlikely to impact the overall survival for the majority of elderly cirrhotic patients, because providing a cure for cirrhosis probably does not affect the natural history of other medical illnesses.

Among the medical co-morbidities, cardiovascular disease adversely impacts a patient's ability to tolerate the stress of the surgery. Renal insufficiency and malignancy decrease recipients' long-term post-transplant survival under the effect of immunosuppression. These complications can have a profound impact on the quality of life for patients after transplantation. As a result, the evaluation of older candidates who are more likely than younger candidates to suffer from these conditions must be meticulous in order to achieve good clinical outcome.

To exclude significant coronary artery and valvular heart disease, most transplant centers require patients over the age of 50 to undergo stress echocardiography. In an evaluation of 772 liver transplant candidates, older age, in addition to a history of coronary artery disease, hypertension and congestive heart failure, was associated with high-risk myocardial perfusion imaging characteristics [38]. Because of the relatively high false-positive rate of stress testing techniques, most centers require cardiology consultation and cardiac catheterization if the results may impact the patient's transplant candidacy [38]-[40]. Even with such a careful approach, postoperative cardiac complications are not eliminated. In one of the series cited above, where all patients had a careful preoperative cardiac evaluation, $19 \%$ of patients over the age of 70 had a cardiac arrhythmia and $7 \%$ had a myocardial infarction within 7 days of liver transplantation [6]. These rates were noticeably higher than the $7 \%$ arrhythmia and $0 \%$ myocardial infarction among recipients who were younger than 60 years of age.

Because of the increased prevalence of renal dysfunction in the elderly as well as its impact on post-transplant outcomes, it is critical to use the most accurate techniques to evaluate renal function in older liver transplant candidates. There is no consensus as to the best approach to estimate renal function as reflected by GFR in elderly patients with cirrhosis who are being considered for liver transplantation. The following is our approach based on empirical evidence. Serum creatinine, urine analysis and urine output remain our most important clinical tools. Serum creatinine, however, usually overestimates true GFR in elderly cirrhotic patients [41], because a normal (or low) serum creatinine could be related to low muscle mass, which is associated with both cirrhosis and aging [42]. As a result, we use 24-hour urine collection to measure creatinine clearance to estimate renal function. While it is likely better than a single measure of serum creatinine, 24-hour creatinine clearance could still overestimate the true GFR [43]. Among the newer methods, measurement of serum cystatin C, a protein produced by all nucleated cells at a constant rate and not affected by gender, age or muscle mass, may be better than serum creatinine [44], although this requires further confirmation. If noninvasive techniques identify significant renal dysfunction, it may be necessary to perform a kidney biopsy in order to determine whether the patient requires combined liver and kidney transplantation rather than liver transplantation alone [45]. 
Besides cross-sectional imaging of the abdomen to screen for hepatocellular cancer in all patients with cirrhosis, cancer screening of elderly transplant candidates focuses on the common cancers in the general population: colonoscopy for colorectal cancer, mammography for breast cancer and chest X-ray for lung cancer. Transvaginal ultrasound is used to screen for gynecological cancers in patients who are at high risk. Patients with previously "cured" extra-hepatic malignancies usually need to be cancer-free for 2 years before being eligible for liver transplantation, although this varies by tumor type. We usually require an oncology consultation to assess the risk of tumor recurrence for patients who had a recent diagnosis of cancer [1].

In addition to screening for common cancers in the general population, two groups of elderly liver transplant candidates require additional testing. The first are patients with primary sclerosing cholangitis (PSC), a rare liver disease that has a relatively high incidence rate among those older than 60 years of age [46]. Patients with PSC carry an increased risk of gallbladder cancer, cholangiocarcinoma and colorectal cancer (among those with concurrent inflammatory bowel disease) [47]. While there is no consensus on the optimal screening strategy, we employ magnetic resonance imaging every 6 months as well as annual surveillance colon biopsies. The second are patients with an established diagnosis of hepatocellular carcinoma, a condition that is strongly associated with advanced age [48]. Because tumor progression is often unpredictable, we employ every 3 months crosssectional imaging plus alpha-fetoprotein measurement to ensure one's tumor burden has not exceeded the standard Milan criteria for transplantation [49]. We also require a chest CT every 6 months to evaluate for pulmonary metastasis.

Finally, frailty, a loosely defined term associated with decreased functional and nutritional status, a feature seen more commonly among elderly patients [21], deserves special consideration. Recently, Englesbe et al. provided rather dramatic data on the relationship between a decrease in psoas muscle area, one of the markers for frailty, and post-liver transplant mortality [50]. The authors not only confirmed that psoas muscle area decreased significantly with increasing age, but also showed that liver transplant recipients whose psoas muscle measured in the lowest quartile had a 1 and 3-year survival of 50\% and $27 \%$, compared to $87 \%$ and $77 \%$ for those in the highest quartile. While we have not routinely used psoas muscle measurement during our evaluation, we employ the more traditional "subjective global assessment" based on 25 parameters obtained from patients' history, physical exam and clinical conditions [51]. In general, we do not consider frail elderly patients with significantly decreased functional status transplant candidates, even when there are no serious medical co-morbidities.

\subsection{After Medical Evaluation: Listing and Peri-Transplant Considerations for Elderly Candidates}

For elderly patients with good functional status and without medical contraindications, it would be reasonable to list them for liver transplantation for the same indications as younger patients. The current liver organ allocation system uses the Model for End Stage Liver Disease (MELD) score, originally developed to predict mortality after transjugular intrahepatic portal systemic shunt procedure [52]. Because MELD score can also accurately predict the risk of death in patients with chronic liver diseases in general [53], those with higher scores, who are more likely to die within 3 months, are given priority for transplant if an organ becomes available. Careful follow-up studies have shown a significant survival benefit from transplantation only in patients with MELD scores of 16 or greater [54], probably because those with lower MELD scores are unlikely to die in the short-term. Given the high-risk nature of the surgery, the benefit of transplantation for patients with low MELD score is less apparent. Thus, it is imprudent to actively list elderly patients with low MELD scores unless they have other compelling indications for transplant.

Being listed for transplant does not ensure that one will be transplanted. Between 2005-2009, 23.6\% of listed patients with a MELD score between 27 - 29 died or became too ill while waiting. Whether elderly listed candidates are more likely to deteriorate clinically compared to younger patients is unclear, but it is critical to identify and avoid transplanting elderly patients who have become too ill to tolerate the surgery and high dose immunosuppression. In an analysis of over 8000 liver transplant recipients 60 years of age or older in the United States from 1994 to 2005, Aloia and colleagues identified five factors that had the greatest impact on post-transplant survival [55]. These five factors, which they combined into an Older Recipient Prognostic Score (ORPS), included ventilator status, diabetes mellitus, hepatitis $C$ infection, serum creatinine $\geq 1.6 \mathrm{mg} / \mathrm{dL}$ and combined recipient and donor age $\geq 120$ years. By assigning 1 point to each factor, patients with $0-2$ points had 1 and 5 -year post-transplant survival rates of $75 \%$ and $58 \%$, respectively. In contrast, elderly recipients with $>2$ ORPS points had a 5-year survival rate less than 50\%. Among these five variables, the combined recipient-donor age $\geq$ 
120 carried the highest risk (hazard ratio 1.49, 95\% confidence interval 1.33 - 1.66), suggesting that it may be prudent to avoid using older donors in older candidates.

Using data from almost 22,000 liver transplant recipients between 2002 and 2006, Rana et al. developed a detailed prognostic system, the Survival Outcomes Following Transplantation (SOFT) score, focusing on factors that have the strongest impact on short-term survival death within 3 months of transplantation [56]. The prognostic variables were assigned between -3 to 14 points. When the SOFT score was less than 5 points, the 3month post-transplant survival was $97 \%$, compared to $38 \%$ when the SOFT score was more than 40 points. Age greater than 70 only resulted in 4 points in this system, notably less than pre-transplant ICU stay (6 points), being on life support (9 points), portal vein thrombosis (5 points) and bleeding from portal hypertension within 48 hours of transplant (6 points) and previous transplants ( 9 and 14 points for 1 and 2 previous transplants, respectively). These data suggest advanced age alone does not portend a poor prognosis after transplantation in the absence of other indicators of disease severity.

By systematic application of these aforementioned prognostic models to elderly patients who have been approved for liver transplantation, it is possible to avoid futile transplants and achieve good post-transplant survival.

\subsection{When Transplantation Is Feasible and Long-Term Survival Is Realistic, Should We Recommend It to Our Elderly Patients? The Special Case of Hepatocellular Carcinoma}

When an elderly patient seems to be a reasonable liver transplant candidate based on the foregoing considerations, there can be circumstances when additional thought should be given to recommending transplantation. One such circumstance is when an elderly patient presents with hepatocellular carcinoma but otherwise well compensated liver disease. The current MELD system in the United States, which provides priority or exception points for patients with hepatocellular carcinoma within the Milan criteria, does not require one to have concurrent decompensated liver disease. Because aging is one of the strongest risk factors for liver cancer development [48], the clinical scenario of liver cancer without liver failure may disproportionately affect elderly patients. If an elderly liver cancer patient has no obvious medical co-morbidities and appears physically well because his or her cirrhosis is well compensated, liver transplantation may seem to be an ideal treatment option. There is, however, strong indirect evidence to suggest that liver transplantation may not be the optimal treatment for this group of patients. De Giorgio et al. reported clinical outcomes in 206 patients with hepatocellular carcinoma within Milan criteria, most of whom received local-regional therapy [57]. The mean age of the cohort was 63, and $75 \%$ of patients had Childs' A cirrhosis. One hundred and twenty three patients were not listed for transplantation, with the most common reason being age 65 or older $(\mathrm{N}=102)$. Over a course of 5 -years, $66 \%$ of unlisted (older) patients remained alive. This rate is in fact better than the 55.5\% 5-year survival reported from the most recent UNOS data on liver transplantation for liver tumor patients age 70 or greater [8]. Given the risk associated with transplantation in terms of donor quality, peri-operative complications and chronic immunosuppression, it is conceivable that elderly liver cancer patients without significant hepatic decompensation may do similarly well with less invasive tumor treatment approaches, such as local regional therapy [3].

\section{Management Considerations for Elderly Patients after Transplantation}

To date, the postoperative management of elderly liver transplant recipients is not significantly different from those for younger recipients. In the future, it may be reasonable to develop protocols specifically tailored to the needs of elderly patients. Important considerations include reduced immunosuppression and a special emphasis on smoking cessation.

The purpose of immunosuppressive medications in liver transplantation is to prevent and treat rejection, a histologically defined condition manifesting host's immune response against the transplanted liver graft. Damages to the donor endothelium and bile ducts are the most common pathological features, usually with associated jaundice and elevated liver enzymes [58] [59]. Even with modern immunosuppression regimen involving calcineurin inhibitors, the rate of acute cellular rejection is in the range of $40 \%-70 \%$ within the first year of liver transplantation [60]-[62]. Interestingly, rejection is usually easily treatable, and the long-term mortality after transplant is less commonly attributed to rejection, but more often to renal failure, cancer, cardiovascular disease and infections [13] [14] [63] [64], all of which may be associated with a weakened immune system.

The elderly liver transplant recipients appear to be at a significantly lower risk of rejection compared younger 
patients. In the most rigorous study to date, in which Wiesner and colleagues systematically analyzed risk factors for histologically confirmed acute rejection among 762 consecutive liver transplant recipients [61], the incidence of rejection was $65 \%$ among recipients age 16 - 29, compared to $34 \%$ among recipients 60 and older. After adjusting for underlying liver disease, immunosuppression regimen and HLA matching, every 10 year increase in recipient age above 30 was associated with a $20 \%$ lower risk of rejection (relative risk $0.81,95 \%$ confidence interval $0.73-0.90$ ).

In contrast to a decreased risk for rejection, elderly liver transplant recipients are at an increased risk for chronic renal failure and malignancies than younger recipients. The incidence of chronic renal failure after liver transplantation increases by $30 \%$ for every decade increase in age, and is strongly associated with post-transplant mortality [64]. Calcineurin inhibitor associated toxicity was the most common cause of renal failure [65]. Several studies have reported a significantly higher risk of de novo malignancies in elderly patients after liver transplantation [11] [63] [66]. Every decade increase in age was associated with a higher risk of non-skin cancer (hazard ratio 2.42, 95\% CI 1.46 - 4.02), which also translated into decreased survival [63].

These studies documenting lower rates of rejection and higher rates of renal failure and malignancies in older recipients would suggest that elderly patients may derive a survival benefit from less immunosuppressive medications. However, there are no published data that specifically address this hypothesis. Calcineurin inhibitor minimization may improve renal function [67], but whether it decreases de novo cancer is unknown. While this may be a rational consideration, the effect of aging may be so strong that minimizing immunosuppression may not alter the risk of malignancies post transplantation.

An extraordinarily strong risk factor for post-transplant malignancies that has been reported in many studies is continuation of smoking after the operation. In fact, the two factors that show the strongest correlation with postoperative malignancies are smoking and age [63]. Based on these data, routine age appropriate cancer screening, special attention to cancers of the skin and lung, and aggressive programs to maintain abstinence from smoking may be the best options before firm data with regard to immunosuppression minimization become available.

\section{Conclusion and Future Directions}

While patients older than age 60, on average, did not do as well as younger patients after liver transplantation historically, optimizing patient selection could minimize this discrepancy. It would be appropriate to evaluate functional elderly patients without significant medical co-morbidities for transplantation for the same indications as younger patients. But for elderly patients with hepatocellular carcinoma and otherwise compensated liver disease, it is important to consider alternative tumor treatment modalities that could provide a similar survival. Elderly candidates who become too ill should be compassionately counseled away from transplantation. What is more devastating than death itself is death after a prolonged post-transplant hospital course, particularly when this could be predicted before the operation. Finally, elderly transplant candidates and recipients may benefit from a more tailored management strategy in terms of donor risk matching and less immunosuppression posttransplantation. The effect of these interventions should undergo more rigorous study.

\section{References}

[1] Murray, K.F. and Carithers Jr., R.L. (2005) AASLD Practice Guidelines: Evaluation of the Patient for Liver Transplantation. Hepatology, 41, 1407-1432. http://dx.doi.org/10.1002/hep.20704

[2] UNOS (2010) United Network for Organ Sharing. http://www.unos.org

[3] Perkins, J.D. (2012) Treatment of an Elderly Patient with Hepatocellular Carcinoma: Counseling from the Patient's Point of View. Liver Transplantation, 18, 391-394. http://dx.doi.org/10.1002/lt.23417

[4] Schwartz, J.J., Pappas, L., Thiesset, H.F., Vargas, G., Sorensen, J.B., Kim, R.D., Hutson, W.R., Boucher, K. and Box, T. (2012) Liver Transplantation in Septuagenarians Receiving Model for End-Stage Liver Disease Exception Points for Hepatocellular Carcinoma: The National Experience. Liver Transplantation, 18, 423-433. http://dx.doi.org/10.1002/lt.23385

[5] Starzl, T.E., et al. (1987) Liver Transplantation in Older Patients. New England Journal of Medicine, 316, 484-485. http://dx.doi.org/10.1056/NEJM198702193160814

[6] Aduen, J.F., Sujay, B., Dickson, R.C., Heckman, M.G., Hewitt, W.R., Stapelfeldt, W.H., Steers, J.L., Harnois, D.M. and Kramer, D.J. (2009) Outcomes after Liver Transplant in Patients Aged 70 Years or Older Compared with Those Younger Than 60 Years. Mayo Clinic Proceedings, 84, 973-978. http://dx.doi.org/10.1016/S0025-6196(11)60667-8 
[7] Rudich, S. and Busuttil, R. (1999) Similar Outcomes, Morbidity, and Mortality for Orthotopic Liver Transplantation between the Very Elderly and the Young. Transplantation Proceedings, 31, 523-552. http://dx.doi.org/10.1016/S0041-1345(98)01537-1

[8] Schwartz, J.J., Thiesset, H., Box, T., Hutson, W. and Sorensen, J. (2012) Liver Transplantation in Septuagenarians Receiving Meld Exception Points for Hepatocellular Carcinoma: The National Experience. Liver Transplantation, 18, 1395-1396. http://dx.doi.org/10.1002/lt.23513

[9] Lipshutz, G.S., Hiatt, J., Ghobrial, R.M., Farmer, D.G., Martinez, M.M., Yersiz, H., Gornbein, J. and Busutti, R.W. (2007) Outcome of Liver Transplantation in Septuagenarians: A Single-Center Experience. Archives of Surgery, 142, 775-784. http://dx.doi.org/10.1001/archsurg.142.8.775

[10] Bjøro, K., Höckerstedt, K., Ericzon, B.G., Friman, S., Hjortrup, A., Keiding, S., Schrumpf, E., Duraj, F., Olausson, M., Mäkisalo, H., Bergan, A. and Kirkegaard, P. (2000) Liver Transplantation in Patients over 60 Years of Age. Transplant International, 13, S165-170. http://dx.doi.org/10.1111/j.1432-2277.2000.tb02012.x

[11] Herrero, J.I., Lucena, J.F., Quiroga, J., Sangro, B., Pardo, F., Rotellar, F., Alvárez-Cienfuegos, J. and Prieto, J. (2003) Liver Transplant Recipients Older Than 60 Years Have Lower Survival and Higher Incidence of Malignancy. American Journal of Transplantation, 3, 1407-1412. http://dx.doi.org/10.1046/j.1600-6143.2003.00227.x

[12] Bromley, P.N., et al. (1994) Orthotopic Liver Transplantation in Patients over 60 Years Old. Transplantation, 58, 800-803. http://dx.doi.org/10.1097/00007890-199410000-00009

[13] Collins, B.H., et al. (2000) Long-Term Results of Liver Transplantation in Older Patients 60 Years of Age and Older. Transplantation, 70, 780-783. http://dx.doi.org/10.1097/00007890-200009150-00012

[14] Cross, T.J., Antoniades, C.G., Muiesan, P., Al-Chalabi, T., Aluvihare, V., Agarwal, K., Portmann, B.C., Rela, M., Heaton, N.D., O’Grady, J.G. and Heneghan, M.A. (2007) Liver Transplantation in Patients over 60 and 65 Years: An Evaluation of Long-Term Outcomes and Survival. Liver Transplantation, 13, 1382-1388. http://dx.doi.org/10.1002/lt.21181

[15] Emre, S., et al. (1993) Liver Transplantation in Patients beyond Age 60. Transplantation Proceedings, 25, $1075-1076$.

[16] Filipponi, F., Roncella, M., Boggi, U., Pietrabissa, A., Romagnoli, J., Urbani, L., Biancofiore, G. and Mosca, F. (2001) Liver Transplantation in Recipients over 60. Transplantation Proceedings, 33, 1465-1466. http://dx.doi.org/10.1016/S0041-1345(00)02552-5

[17] Garcia, C.E., Garcia, R.F.L., Mayer, A.D. and Neuberger, J. (2001) Liver Transplantation in Patients over Sixty Years of Age. Transplantation, 72, 679-684. http://dx.doi.org/10.1097/00007890-200108270-00021

[18] Levy, M.F., Somasundar, P.S., Jennings, L.W., Jung, G.J., Molmenti, E.P., Fasola, C.G., et al. (2001) The Elderly Liver Transplant Recipient: A Call for Caution. Annals of Surgery, 233, 107-113. http://dx.doi.org/10.1097/00000658-200101000-00016

[19] Pirsch, J.D., Kalayoglu, M., D’Alessandro, A.M., Voss, B.J., Armbrust, M.J., Reed, A., Knechtle, S.J., Sollinger, H.W. and Belzer, F.O. (1991) Orthotopic Liver Transplantation in Patients 60 Years of Age and Older. Transplantation, 51, 431-433. http://dx.doi.org/10.1097/00007890-199102000-00031

[20] Stieber, A.C., Gordon, R.D., Todo, S., Tzakis, A.G., Fung, J.J., Casavilla, A., Selby, R.R., Mieles, L., Reyes, J. and Starzl, T.E. (1991) Liver Transplantation in Patients over Sixty Years of Age. Transplantation, 51, 271-273. http://dx.doi.org/10.1097/00007890-199101000-00046

[21] Zetterman, R.K., Belle, S.H., Hoofnagle, J.H., Lawlor, S., Wei, Y.L., Everhart, J., Wiesner, R.H. and Lake, J.R. (1998) Age and Liver Transplantation: A Report of the Liver Transplantation Database. Transplantation, 66, 500-506. http://dx.doi.org/10.1097/00007890-199808270-00015

[22] Yoshizumi, T., Shirabe, K., Soejima, Y., Taketomi, A., Yamashita, N., Ikegami, T., Uchiyama, H., Kayashima, H., Ninomiya, M. and Maehara, Y. (2010) Living Donor Liver Transplantation in Patients Older than 60 Years. Transplantation, 90, 433-437. http://dx.doi.org/10.1097/TP.0b013e3181e81b2d

[23] Keswani, R.N., Ahmed, A. and Keeffe, E.B. (2004) Older Age and Liver Transplantation: A Review. Liver Transplantation, 10, 957-967. http://dx.doi.org/10.1002/lt.20155

[24] Harrison, J., McKiernan, J. and Neuberger, J.M. (1997) A Prospective Study on the Effect of Recipient Nutritional Status on Outcome in Liver Transplantation. Transplant International, 10, 369-374. http://dx.doi.org/10.1111/j.1432-2277.1997.tb00931.x

[25] Nair, S., Verma, S. and Thuluvath, P.J. (2002) Pretransplant Renal Function Predicts Survival in Patients Undergoing Orthotopic Liver Transplantation. Hepatology, 35, 1179-1185. http://dx.doi.org/10.1053/jhep.2002.33160

[26] Odden, M.C., Coxson, P.G., Moran, A., Lightwood, J.M., Goldman, L. and Bibbins-Domingo, K. (2011) The Impact of the Aging Population on Coronary Heart Disease in the United States. American Journal of Medicine, 124, 827-833.e5. 
[27] Epstein, M. (1996) Aging and the Kidney. Journal of the American Society of Nephrology, 7, 1106-1122.

[28] Looker, A.C., Melton III, L.J., Harris, T.B., Borrud, L.G. and Shepherd, J.A. (2010) Prevalence and Trends in Low Femur Bone Density among Older US Adults: NHANES 2005-2006 Compared with NHANES III. Journal of Bone and Mineral Research, 25, 64-71. http://dx.doi.org/10.1359/jbmr.090706

[29] Yancik, R. (1997) Cancer Burden in the Aged: An Epidemiologic and Demographic Overview. Cancer, 80, $1273-1283$. http://dx.doi.org/10.1002/(SICI)1097-0142(19971001)80:7<1273::AID-CNCR13>3.0.CO;2-4

[30] Berry, J.D., Dyer, A., Cai, X., Garside, D.B., Ning, H.y., Thomas, A., Greenland, P., Van Horn, L., Tracy, R.P. and Lloyd-Jones, D.M. (2012) Lifetime Risks of Cardiovascular Disease. New England Journal of Medicine, 366, 321-329. http://dx.doi.org/10.1056/NEJMoa1012848

[31] Lindeman, R.D., Tobin, J. and Shock, N.W. (1985) Longitudinal Studies on the Rate of Decline in Renal Function with Age. Journal of the American Geriatrics Society, 33, 278-285.

[32] Esposito, C., Plati, A., Mazzullo, T., Fasoli, G., De Mauri, A., Grosjean, F., Mangione, F., Castoldi, F., Serpieri, N., Cornacchia, F. and Dal Canton, A. (2007) Renal Function and Functional Reserve in Healthy Elderly Individuals. Journal of Nephrology, 20, 617-625.

[33] Luft, F.C., Grim, C.E., Fineberg, N. and Weinberger, M.C. (1979) Effects of Volume Expansion and Contraction in Normotensive Whites, Blacks, and Subjects of Different Ages. Circulation, 59, 643-650. http://dx.doi.org/10.1161/01.CIR.59.4.643

[34] Coresh, J., Selvin, E., Stevens, L.A., Manzi, J., Kusek, J.W., Eggers, P., Van Lente, F. and Levey, A.S. (2007) Prevalence of Chronic Kidney Disease in the United States. JAMA, 298, 2038-2047. http://dx.doi.org/10.1001/jama.298.17.2038

[35] Sokhi, R.P., Anantharaju, A., Kondaveeti, R., Creech, S.D., Islam, K.K. and Van Thiel, D.H. (2004) Bone Mineral Density among Cirrhotic Patients Awaiting Liver Transplantation. Liver Transplantation, 10, 648-653. http://dx.doi.org/10.1002/lt.20104

[36] Hui, S.L., Slemenda, C.W. and Johnston Jr., C.C. (1988) Age and Bone Mass as Predictors of Fracture in a Prospective Study. Journal of Clinical Investigation, 81, 1804-1809. http://dx.doi.org/10.1172/JCI113523

[37] Hoshida, Y., Ikeda, K., Kobayashi, M., Suzuki, Y., Tsubota, A., Saitoh, S., et al. (1999) Chronic Liver Disease in the Extremely Elderly of 80 Years or More: Clinical Characteristics, Prognosis and Patient Survival Analysis. Journal of Hepatology, 31, 860-866. http://dx.doi.org/10.1016/S0168-8278(99)80287-6

[38] Bradley, S.M., Soine, L.A., Caldwell, J.H. and Goldberg, S.L. (2010) Screening Stress Myocardial Perfusion Imaging and Eligibility for Liver Transplantation. American Journal of Cardiology, 105, 1010-1013. http://dx.doi.org/10.1016/j.amjcard.2009.11.023

[39] Ehtisham, J., Altieri, M., Salamé, E., Saloux, E., Ollivier, I. and Hamon, M. (2010) Coronary Artery Disease in Orthotopic Liver Transplantation: Pretransplant Assessment and Management. Liver Transplantation, 16, 550-557.

[40] Tiukinhoy-Laing, S.D., Rossi, J.S., Bayram, M., De Luca, L., Gafoor, S., Blei, A., Flamm, S., Davidson, C.J. and Gheorghiade, M. (2006) Cardiac Hemodynamic and Coronary Angiographic Characteristics of Patients Being Evaluated for Liver Transplantation. American Journal of Cardiology, 98, 178-181. http://dx.doi.org/10.1016/j.amjcard.2006.01.089

[41] Caregaro, L., Menon, F., Angeli, P., Amodio, P., Merkel, C., Bortoluzzi, A., Alberino, F. and Gatta, A. (1994) Limitations of Serum Creatinine Level and Creatinine Clearance as Filtration Markers in Cirrhosis. JAMA Internal Medicine, 154, 201-205. http://dx.doi.org/10.1001/archinte.1994.00420020117013

[42] Koopman, R. and van Loon, L.J. (2009) Aging, Exercise, and Muscle Protein Metabolism. Journal of Applied Physiology, 106, 2040-2048. http://dx.doi.org/10.1152/japplphysiol.91551.2008

[43] Proulx, N.L., Akbari, A., Garg, A.X., Rostom, A., Jaffey, J. and Clark, H.D. (2005) Measured Creatinine Clearance from Timed Urine Collections Substantially Overestimates Glomerular Filtration Rate in Patients with Liver Cirrhosis: A Systematic Review and Individual Patient Meta-Analysis. Nephrology Dialysis Transplantation, 20, 1617-1622. http://dx.doi.org/10.1093/ndt/gfh839

[44] Gerbes, A.L., Gülberg, V., Bilzer, M. and Vogeser, M. (2002) Evaluation of Serum Cystatin C Concentration as a Marker of Renal Function in Patients with Cirrhosis of the Liver. Gut, 50, 106-110. http://dx.doi.org/10.1136/gut.50.1.106

[45] Eason, J.D., Gonwa, T.A., Davis, C.L., Sung, R.S., Gerber, D. and Bloom, R.D. (2008) Proceedings of Consensus Conference on Simultaneous Liver Kidney Transplantation (SLK). American Journal of Transplantation, 8, $2243-2251$. http://dx.doi.org/10.1111/j.1600-6143.2008.02416.x

[46] Toy, E., Balasubramanian, S., Selmi, C., Li, C.S. and Bowlus, C.L. (2011) The Prevalence, Incidence and Natural History of Primary Sclerosing Cholangitis in an Ethnically Diverse Population. BMC Gastroenterology, 11, 83. http://dx.doi.org/10.1186/1471-230X-11-83 
[47] Chapman, R., Fevery, J., Kalloo, A., Nagorney, D.M., Muri Boberg, K., Shneider, B. and Gores, G.J. (2010) Diagnosis and Management of Primary Sclerosing Cholangitis. Hepatology, 51, 660-678. http://dx.doi.org/10.1002/hep.23294

[48] Asahina, Y., Tsuchiya, K., Tamaki, N., Hirayama, I., Tanaka, T., Sato, M., Yasui, Y., et al. (2010) Effect of Aging on Risk for Hepatocellular Carcinoma in Chronic Hepatitis C Virus Infection. Hepatology, 52, 518-527. http://dx.doi.org/10.1002/hep.23691

[49] Mazzaferro, V., Regalia, E., Doci, R., Andreola, S., Pulvirenti, A., Bozzetti, F., Montalto, F., Ammatuna, M., Morabito, A. and Gennari, L. (1996) Liver Transplantation for the Treatment of Small Hepatocellular Carcinomas in Patients with cirrhosis. New England Journal of Medicine, 334, 693-699. http://dx.doi.org/10.1056/NEJM199603143341104

[50] Englesbe, M.J., Patel, S.P., He, K., Lynch, R.J., Schaubel, D.E., Harbaugh, C., Holcombe, S.A., Wang, S.C., Segev, D.L. and Sonnenday, C.J. (2010) Sarcopenia and Mortality after Liver Transplantation. Journal of the American College of Surgeons, 211, 271-278. http://dx.doi.org/10.1016/j.jamcollsurg.2010.03.039

[51] Hasse, J., Strong, S., Gorman, M.A. and Liepa, G. (1993) Subjective Global Assessment: Alternative Nutrition-Assessment Technique for Liver-Transplant Candidates. Nutrition, 9, 339-343.

[52] Malinchoc, M., Kamath, P.S., Gordon, F.D., Peine, C.J., Rank, J. and ter Borg, P.C.J. (2000) A Model to Predict Poor Survival in Patients Undergoing Transjugular Intrahepatic Portosystemic Shunts. Hepatology, 31, 864-871. http://dx.doi.org/10.1053/he.2000.5852

[53] Kamath, P.S., Wiesner, R.H., Malinchoc, M., Kremers, W., Therneau, T.M., Kosberg, C.L., D’Amico, G., Dickson, E.R. and Kim, W.R. (2001) A Model to Predict Survival in Patients with End-Stage Liver Disease. Hepatology, 33, 464-470. http://dx.doi.org/10.1053/jhep.2001.22172

[54] Merion, R.M., Schaubel, D.E., Dykstra, D.M., Freeman, R.B., Port, F.K. and Wolfe, R.A. (2005) The Survival Benefit of Liver Transplantation. American Journal of Transplantation, 5, 307-313. http://dx.doi.org/10.1111/j.1600-6143.2004.00703.x

[55] Aloia, T.A., Knight, R., Gaber, A.O., Ghobria, R.M. and Goss, J.A. (2010) Analysis of Liver Transplant Outcomes for United Network for Organ Sharing Recipients 60 Years Old or Older Identifies Multiple Model for End-Stage Liver Disease-Independent Prognostic Factors. Liver Transplantation, 16, 950-959. http://dx.doi.org/10.1002/lt.22098

[56] Rana, A., Hardy, M.A., Halazun, K.J., Woodland, D.C., Ratner, L.E., Samstein, B., Guarrera, J.V., Brown Jr., R.S. and Emond, J.C. (2008) Survival Outcomes Following Liver Transplantation (SOFT) Score: A Novel Method to Predict Patient Survival Following Liver Transplantation. American Journal of Transplantation, 8, 2537-2546. http://dx.doi.org/10.1111/j.1600-6143.2008.02400.x

[57] De Giorgio, M., Vezzoli, S., Cohen, E., Armellini, E., Lucà, M.G., Verga, G., Pinelli, D., Nani, R., Valsecchi, M.G., Antolini, L., Colledan, M., Fagiuoli, S. and Strazzabosco, M. (2010) Prediction of Progression-Free Survival in Patients Presenting with Hepatocellular Carcinoma within the Milan Criteria. Liver Transplantation, 16, 503-512.

[58] (1997) Banff Schema for Grading Liver Allograft Rejection: An International Consensus Document. Hepatology, 25, 658-663. http://dx.doi.org/10.1002/hep.510250328

[59] Henley, K.S., Lucey, M.R., Appelman, H.D., Baliga, P., Brown, K.A., Burtch, G.D., Campbell Jr., D.A., Ham, J.M., Merion, R.M. and Turcotte, J.G. (1992) Biochemical and Histopathological Correlation in Liver Transplant: The First 180 Days. Hepatology, 16, 688-693. http://dx.doi.org/10.1002/hep.1840160312

[60] The U.S. Multicenter FK506 Liver Study Group (1994) A Comparison of Tacrolimus (FK 506) and Cyclosporine for Immunosuppression in Liver Transplantation. New England Journal of Medicine, 331, 1110-1115. http://dx.doi.org/10.1056/NEJM199410273311702

[61] Wiesner, R.H., Demetris, A.J., Belle, S.H., Seaberg, E.C., Lake, J.R., Zetterman, R.K., Everhart, J. and Detre, K.M. (1998) Acute Hepatic Allograft Rejection: Incidence, Risk Factors, and Impact on Outcome. Hepatology, 28, 638-645. http://dx.doi.org/10.1002/hep.510280306

[62] European FK506 Multicentre Liver Study Group (1994) Randomised Trial Comparing Tacrolimus (FK506) and Cyclosporin in Prevention of Liver Allograft Rejection. Lancet, 344, 423-428. http://dx.doi.org/10.1016/S0140-6736(94)91766-3

[63] Herrero, J.I., Lorenzo, M., Quiroga, J., Sangro, B., Pardo, F., Rotellar, F., Alvarez-Cienfuegos, J. and Prieto, J. (2005) De Novo Neoplasia after Liver Transplantation: An Analysis of Risk Factors and Influence on Survival. Liver Transplantation, 11, 89-97. http://dx.doi.org/10.1002/lt.20319

[64] Ojo, A.O., Held, P.J., Port, F.K., Wolfe, R.A., Leichtman, A.B., Young, E.W., Arndorfer, J., Christensen, L. and Merion, R.M. (2003) Chronic Renal Failure after Transplantation of a Nonrenal Organ. New England Journal of Medicine, 349, 931-940. http://dx.doi.org/10.1056/NEJMoa021744

[65] Gonwa, T.A., Mai, M.L., Melton, L.B., Hays, S.R., Goldstein, R.M., Levy, M.F. and Klintmalm, G.B. (2001) EndStage Renal Disease (ESRD) after Orthotopic Liver Transplantation (OLTX) Using Calcineurin-Based Immunotherapy: Risk of Development and Treatment. Transplantation, 72, 1934-1939. 
http://dx.doi.org/10.1097/00007890-200112270-00012

[66] Jain, A., Patil, V.P. and Fung, J. (2008) Incidence of de Novo Cancer and Lymphoproliferative Disorders after Liver Transplantation in Relation to Age and Duration of Follow-Up. Liver Transplantation, 14, 1406-1411. http://dx.doi.org/10.1002/lt.21609

[67] Mackay, A.J., Angus, P.W. and Gow, P.J. (2011) Long-Term Outcomes of Calcineurin Inhibitor Withdrawal for PostLiver Transplant Renal Dysfunction. Transplantation Proceedings, 43, 3802-3806.

http://dx.doi.org/10.1016/j.transproceed.2011.10.044 
Scientific Research Publishing (SCIRP) is one of the largest Open Access journal publishers. It is currently publishing more than 200 open access, online, peer-reviewed journals covering a wide range of academic disciplines. SCIRP serves the worldwide academic communities and contributes to the progress and application of science with its publication.

Other selected journals from SCIRP are listed as below. Submit your manuscript to us via either submit@scirp.org or Online Submission Portal.
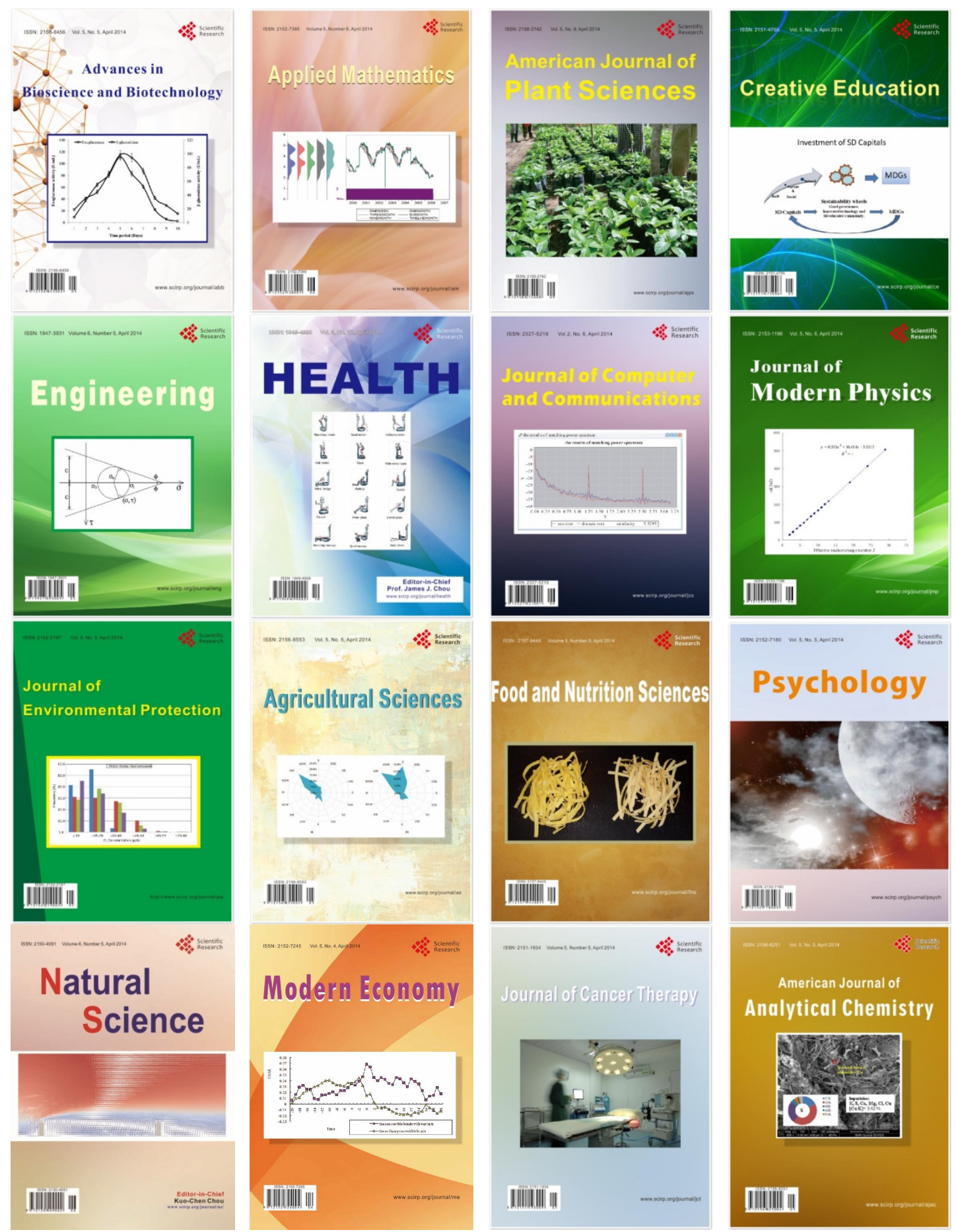